\title{
ECOSANDALS.COM: THE DIGITAL TRANSFORMATION OF A SOCIAL ENTERPRISE ${ }^{1}$
}

\author{
How can a social enterprise evolve a digitally-enabled operating model?
}

The Wikyo Akala Project (WAP) was a cooperative set up as a social enterprise that sought to pool the efforts of the sandal makers in the Korogocho area, Nairobi, Kenya, in order to improve their sales revenue using the internet platform. WAP struggled to survive as a "bricks-and-mortar" social enterprise in the first six years of operation. However, with the adoption of a "clicks-and-mortar" digital strategy through an e-commerce platform, the project witnessed phenomenal growth as the internet architecture provided them with an opportunity to re-think their operating model.

The digital platform for WAP was called Ecosandals.com and it was reliant on volunteers in the global North who assisted this social enterprise in the global South. The volunteers provided technical assistance as well as business expertise. The piloting of the Ecosandals.com e-commerce site in February 2001 saw significant growth in labour capacity at WAP (from 5 to 30 sandal makers) and revenue. There were also major increases in international sales, with the selling price increasing from barely 15 US cents to over 40 US dollars per pair of sandals in some instances.

With the success of the piloting of the Ecosandals.com platform there were several decisions pertaining to the transformation of the social enterprise that needed to be addressed. The digital technology driven business model would have a wide ranging effect on their business model and the products that the sandal makers would produce. The key questions and decisions that faced them were the following:

1. Which operating model would be appropriate for their social enterprise operating in a resourceconstrained environment?

2. Secondly, how could they incorporate digital technology into the standardization of their services and processes, and to enable integration of their processes?

3. And thirdly the issue of future growth, sustainability and competition needed to be addressed.

\footnotetext{
${ }^{1}$ Copyright (C 2018, Nixon Muganda Ochara. This case was prepared for the purpose of class discussion. Names and some information have been disguised. This case is published under a Creative Commons BY-NC license and originally appeared as a chapter in Transforming Society Using ICT: Contemporary Discussion Cases from Africa. Permission is granted to copy and distribute this case for non-commercial purposes, in both printed and electronic formats.
} 


\section{Country Context}

The nation of Kenya shared borders with Ethiopia, Sudan, Uganda, Tanzania and Somalia (Exhibit 1). The population groups in Kenya were mainly black Africans (99\%), with a small number of non-Africans (1\%). The two official languages were Kiswahili and English. Kiswahili was the main language for conducting business transactions and was also used in government offices since, for $99 \%$ of the population, English was a second, third or even fourth language. Exhibit 2 summarizes key statistics about the nation of Kenya.

Kenya's economy had been growing steadily since 2003 (4.9\% in 2004; 5.8\% in 2005; and 6.1\% in 2006; estimated growth for 2017 was 6.3\%). The services sector had always played an important role in the growth of the economy.

The history of the internet in Kenya dated as far back as 1994 when the African Regional Centre for Computing (ARCC) was set up to offer full internet connectivity in the country through the support of the US National Science Foundation. The liberalization of the sector also resulted in the creation of a National Task Force on electronic commerce in May 1999 with a view to providing an enabling environment for electronic trade in the country. As a result, awareness of the potential of the internet and other related ICT services such as e-government, increased. Many stakeholders indicated interests in applying the internet in their businesses. The establishment of Ecosandals.com in early 2000s could be linked to the efforts to establish and expand the internet infrastructure, which provided an enabling environment for e-commerce growth.

\section{Social Entrepreneurship and Founding of Ecosandals.com}

\section{The Predecessors to Ecosandals.com}

In the past, social enterprises were modeled on the tenets of 'not-for-profit' organizations that attracted human and social capital with pro-social, community-spirited motives, but unfortunately engendered survival strategies premised on grant dependency (Chell, 2007). More recent perspectives on the nature of social enterprises viewed them as a form of entrepreneurship that were self-sustaining and sometimes profit driven with the goal of creating 'social and economic value' (Chell, 2007). The latter perspective emboldened social enterprise entrepreneurs to explore hybrid configurations, where a social enterprise operated on an economic model for financial sustainability. The digital transformation of Ecosandals.com needed to be viewed from this hybrid perspective; where, from an economic perspective they sought sustainable growth of their business, while from a social perspective, they sought to uplift the community out of poverty using inputs from philanthropy and volunteers.

The establishment of Ecosandals.com coincided with the introduction of the internet to Kenya by the African Regional Centre for Computing (ARCC), which was run as an NGO by Dr. Shem Ochuodho,; as well as the establishment of Africa Online as the first commercial internet Service Provider (ISP) in Kenya. WAP, the pre-cursor to Ecosandals.com, was started in 1995 as a social enterprise by Benson Wikyo and Mathew Mayer. Benson Wikyo was a social worker based in Nairobi, Kenya, and Mathew Meyer, an American student from Brown University, was on a study-abroad program in Kenya. Mathew Meyer was studying Swahili and sought to gain experience in how the language was used by embedding himself in Korogocho, a poverty stricken area in Nairobi designated as a "slum". 
Benson Wikyo, as a social worker, had over the years interacted and counseled many residents of Korogocho and therefore understood the extent and the impact of poverty on the lives of the residents of Korogocho. The experience of poverty and destitution in the Korogocho slums led Mathew and Benson to reflect on the role they could play to improve the lives of the residents of Korogocho. Having worked and lived in the area for many years, Benson was aware that many residents were involved in various small enterprises such as making sandals made from discarded used rubber tires. Mathew and Benson partnered to focus their efforts on improving the quality of the lives of a group of sandals makers by starting the WAP cooperative in 1995.

WAP was setup as a social enterprise targeted towards improving the lives of sandal makers by pooling their resources and efforts. The project was used for training young and unemployed members of the community on the production and sale of sandals from used car tires. Ultimately, WAP sought to raise capital for the Korogocho community through the sale of these sandals. The establishment of the project was based on elements of sustainability by integrating education, human capital development and the protection of the environment using recycled materials, especially tires. The project was initially named Korogocho Akala Projects. Benson was tasked with handling the production aspects of the project while Mathew handled the marketing component of the enterprise. Following the unexpected and tragic death in 1998 of the Kenyan co-founder Kenyan (i.e. Benson Wikyo), Mathew Meyer worst fears of witnessing the death of their project came true albeit for a brief period.

However, a few weeks after the burial of Benson Wikyo, Patrick Mukoya, a community member and a friend of Benson came forth with a proposal to restart the project with his seed grant money. The project re-started and was re-named the Wikyo Akala Project (after the former co-founder), with Patrick Mukoya as the Project Director. Following the re-launch, the project resumed its core business of making beaded sandals (see Exhibit 3). Beyond making beaded sandals, the Wikyo Akala Project (WAP) also trained its staff and community members in basic skills in English, Mathematics, Business Skills and Computer Skills. Thus, while the core business was manufacturing and selling beaded sandals, a secondary activity of WAP was the role it played as an informal school that sought to contribute towards improving the dignity of the community members, most of whom were school dropouts.

Despite the re-launch and the revived impetus provided by the new Project Director, WAP still struggled to survive. Its communications facilities consisted of inadequate computer and fax equipment, and the phone rarely worked. The office struggled, but the persistence and creativity of the sandals makers ensured that sales continued to trickle in to sustain themselves and the aim of the project.

Whereas the new Project Director, Patrick Mukoya, focused his energies on Benson's former role of manufacturing the sandals, Mathew Meyer retained his role of marketing the enterprise. Sandal making from used car tires had a long tradition, not only in Kenya but in many other African countries. Recycling used car tires was just one of the many recycled products derived from waste in many developing countries. As Mathew Meyer noted:

For many people across our planet who live on less than \$5 per day, scavenging through trash for food and anything of value is about survival. Yet, ironically, the great tragedy of mass poverty begets a culture of recycling and reusing that many in the developed world would do well to imitate.

Sandal making from used car tires was considered to be a mundane, commonplace activity, typically left to school dropouts facing a bleak future, either in furthering their education or being gainfully employed 
(see Exhibit 4). Yet, the informal sector, where a lot of recycling of waste took place, employed multitudes across the continent. So, for Patrick Mukoya, the challenge was not where to get talent for sandal making, but to ensure the production process produced creatively designed sandals that would appeal to a specific clientele with a view to ensuring the sustainability and economic viability of the project. As a consequence, the focus of sandal making training was more on how to design creative and “cool” sandals.

Continuous innovation in the sandal making process was the critical anchor of the operations of WAPcontinuously modifying their product offerings to keep it customer-centric. On the supply-side, the long history of recycling on the continent assured that the delivery of raw materials was not a problem to WAP operations. It had been well established that distribution networks for retreads in Kenya were extensive and accessible (Panchal, 2016).

The initial reason that made Korogocho a strategic location for WAP was access to low-cost production inputs, access to sandal making skills and knowledge, and proximity to the local markets. However, after six years of operation WAP was not realizing the expected and much needed success in sustainability and profitability. It was at this point that Mathew changed the business model. Mathew Meyer realized that the market in Korogocho and Nairobi was not responsive enough to the kind of product design that WAP had in mind. As described by Mathew Meyer:

You're talking about, you know, 300,000 - 400,000 people who are living in huts one right next to the other with dirt alleyways. There are often six or seven people living in a one room hut.

The poverty levels in Korogocho most likely accounted for the low sales during the first six-year period (Gathuthi et al., 2010) when, despite all the best intentions, business growth remained minuscule, the enterprise struggled and the sustainability of the whole project was called into question. Making sandals from used tires had always had very low entry barriers to the extent that in low income environments such as Korogocho, competition was fierce, and was largely based on price. Thus, despite having an innovative operations strategy, the front-end, linked more to marketing, became more and more challenging as Mathew Meyer grappled with competition.

\section{The Founding of Ecosandals.com}

The stagnation in the growth of WAP, despite the injection of capital by Patrick and Mathew, was a concern for the sustainability of the social enterprise. Mathew realized that he needed to define a new customer base for their sandals. He also sought to establish who and what influenced these customers that bought these specific sandals. Sandals from recycled used car tires were generally considered as a lowend product, predominantly linked to the poor who could not afford the much more sophisticated and classy sandals mostly found in shopping malls. Rather, the recycled car tire sandals were to be found in poverty stricken areas, sold in open spaces under the heat of the sun. The Swahili term for working under the heat of the sun is "Jua Kali", and artisans associated with the production of these eco sandals were s a consequence referred to as “Jua Kali” artisans or 'hot sun’ artisans. Therefore, from a “Jua Kali” Kenyan customer's perspective, the eco sandals made by WAP were a "menial" product, meant for the low class, who had no other purchase options. Yet, the additional innovation and creativity that was employed in the sandal making process for WAP's eco-sandals seemed to support a premium price, in comparison to the standard “Jua Kali” products.

Mathew had hoped that their quality design would ultimately attract the customers that they wanted. Eventually, he came to the sad realization that the customer that sought to buy their product either did not exist or did not live in Korogocho. The destitution and depravity was described by Mathew as follows: 
Korogocho, the area that is home to the Wikyo Akala Project, means "hopeless" in the local Kikuyu dialect. Korogocho families, with as many as 10 members, live in single-room huts made of mud or rusted sheets of iron. There is no sanitation system and no piped water. Refuse of all types litters the homes and their surroundings, and the stench of urine often wafts across the neighborhood. Disease runs rampant, as do gun-wielding thieves.

The sad realization that WAP's potential customer was not physically located in Korogocho meant that the sales effort, typically by word-of-mouth for 'Jua Kali' products, would not work for WAP. Advertising through word of mouth would not bring in the sustainable growth that WAP yearned for. WAP's relative price for their sandals was high compared to their local competitors. Mathew therefore sought to identify who their customers were and how they could reach those customers. Beyond identifying potential customers, Mathew wondered what sort of sales targets would be required to reach customers who were most likely not to be based in Korogocho.

Achieving sustainable growth and ensuring a customer base are widely identified as strategic issues in of social enterprises (Albinsson \& Yasanthi, 2012). In addressing the issues of sustainability the directors of WAP faced several decision. For instance, with the commercialization of the internet in the 1990s, how would the operating context of a social enterprise transform to consider the role of the new digital revolution? Mathew sought to find an answer to the issues affecting sales including how technology could be used for improving sales and bolstering revenue. After considering the role the internet (in the early 2000s) played in a social enterprise, Mathew recognized that the internet provided several strategic opportunities that would not only enable WAP to improve its current business revenue, but also to transform completely and redefine itself. As early as 1996, Bloch et al. (1996) had identified organizational improvement, transformation and redefinition as the key value flows that would be derived from the adoption of the internet by commercial sector companies. Mathew wondered if, they could achieve their sustainable growth objectives by employing the internet within their social enterprise.

\section{Finding the Appropriate Business Model for Ecosandals.com}

The time for making difficult decisions had arrived. Mathew, born and raised in the US, and now in partnership thought: we must make something give! Here is a social enterprise which is oriented towards social activism. Nevertheless, the challenges of the operating context demanded that they understand how to adopt the "commercial" mindset in an environmentally friendly way. The challenge of the operating context and sustainability continued to puzzle Mathew. Here is how he voiced his struggle:

Growing up in the U.S., I always thought environmentalists and pro-growth economists were inevitably in conflict. The development of an aggressive capitalist business model, I thought, necessarily involved some amount of degradation of the Earth. But after nearly 10 years of working in the field, I have learned that environmental preservation and, more specifically, trash reduction is critical to the provision of basic daily needs in materially impoverished urban areas of the developing world.

For a social enterprise, there were also concerns about perceptions from the community. From the community's perspective, a social enterprise was viewed as "non-greedy", or not profit-oriented; while from a regulatory perspective, profit making implied paying corporate tax. So, one of the key decisions they needed to make was what the operating model of WAP should be. They grappled with the operating model of WAP since they were faced with the need to create and add value to customers whose identity they still had not established, and they also needed to find the most effective means to market their 
products to these customers. In parallel to this, they also needed to remain a social enterprise that is cognisant of its social activist role.

Mathew's American connections came in handy, they came to the party so to speak. In seeking to move beyond the boundaries of Korogocho as the prime market for their products, Mathew, through his friends in the USA (who eventually became volunteers), decided to develop an online portal for WAP, which was named Ecosandals.com.

Ecosandals.com was set up as an e-commerce site, which, at the very basic level, meant viewing the operations of WAP as a commercial enterprise (and the implications thereof.) The Ecosandals.com site operated almost entirely independently from WAP by handling all customer orders since most of the customers were not within the Kenyan borders. There arose "natural" tensions of course, as Mathew had to set up a merchant account to handle the e-commerce transactions. This meant that e-commerce transactions would be handled independently in the USA, with minimal integration with the Kenyan operations of WAP.

Fortunately, no major issues arose in respect of governance of Ecosandals.com and WAP. WAP, through its partnership with Ecoandals.com, became a multinational organization with a global presence and distributorship channels located around the world.

The development of Ecosandals.com, run by volunteers from Michigan, allowed Mathew Meyer to entrench the principles of operating as a social enterprise, with the volunteers in the North rendering volunteer services that assisted an enterprise in the global South. By linking commerce to environmentalism, the Ecosandals.com portal became the voice through which WAP could link commerce to environmentalism. Mathew Meyer said the following on this topic:

I have always felt that environmentalism in a place like this has to involve forging long-term solutions to existing human problems. Almost everyone would agree that environmentalism is a commitment to leave the planet in better shape for our children. For sandal-makers like Roselyn Egosangwa, who has five children of her own, that sentiment takes on much more urgency. Being an environmentalist in Korogocho is not about saving the planet for generations to come; it is about providing a better life for Roselyn and her five children today.

The business model of WAP and Ecosandals.com can be summarized as follows. The 'community face' of Ecosandals.com sought to remain true to the social mission of operating as a not-for-profit enterprise, yet continuing as a sustainable social enterprise for the long run. The 'environmental face' of Ecosandals.com was clear to the decision makers as they predicated the existence of WAP on the recycling of used rubber tires as the primary raw material for making the eco-friendly sandals. Coupling this social enterprise, premised on recycling and environmental awareness, with an e-commerce platform they were able to achieve sustainability of their enterprise.

\section{Issue of Process Integration and Standardization}

With the launch of Ecosandals.com, and as demand for the products soared, the 8-man operation soon became a 27-man operation, with dozens of volunteers and distributors throughout the world. Ecosandals.com, operating from Michigan, ensured that the demand was sustained; WAP, based in Korogocho, focused on production of the sandals. With such clear demarcations of processes involving customer-ordering and marketing operations located in Michigan and production and capacity operations based in Korogocho, Kenya, there was need to consider the nature and extent of process integration and standardization. 
For the WAP and Ecosandals.com partnership, these two issues needed to be addressed in order to evolve an operating model that could allow both WAP and Ecosandals.com to thrive and grow. The operations of the enterprise needed to meet standards of corporate governance as well as the regulatory and legal requirements of a commercial enterprise operating from two geographic areas. So the overseas operations in North America had to be integrated with the South operations in Kenya. Process standardization would allow them to define how each of their processes were to be executed, regardless of who was performing it or where the process was being performed, that is, in North America or Kenya.

For WAP and Ecosandals.com, this became a challenge, as the process of sandal making and its record keeping was entirely manual while the sales 'front-end' was completely digitized. The linking of the two main processes was therefore dependent on e-mail and VOIP correspondence. Due to the low levels of standardization, delays in translating customer requirements into products was common and remained an issue. In a 2002 posting that appeared in Pambazuka, a publication of WAP, the organization apologized to their customers for delivery delays:

Due to the dramatic increase in orders, we have struggled to keep pace. Perhaps you waited months for your order when we told you it would only be weeks. We are extremely sorry for this.

While they considered the role of digital technology in the integration of their operations, the decision makers also needed to analyze the cost of re-orientation of the organization to a technology-driven platform; also, whether they would be able to sustain such a technology re-orientation from a human capital perspective (Espinosa et al., 2011).

\section{Addressing Future Challenges of Sustainability and Competition}

As demand soared, Mathew and Patrick knew that the operations of WAP and Ecosandals.com should become more and more digital. In addition, it was evident that the growth and the thriving social enterprise could start experiencing far greater sustainability challenges if the enterprise did not respond to the different dynamics brought about by the digital challenges. It was widely recognized that even in enterprises with an embedded social purpose, competition was still experienced by these enterprises (Austin et al., 2006), and the success of WAP and Ecosandals.com was, therefore, bound to invite other competitors. To this end, the decision of Mathew and Patrick in so far as the future of the enterprise and entry of potential competitors was focused on two areas, namely: the operating model and governance mechanisms relevant for successful digital transformation of the enterprise.

With respect to the broader question of the operating model, Mathew Meyer and Patrick Mukoya consulted available literature about what to do. Literature is replete with cases of the different types of operating models, especially for commercial sector organizations (Ross et al., 2006). A decision had to be taken to adopt a purely as a social enterprise model, a for-profit entity model or as a hybrid model. Whilst the two decision makers accepted that the social enterprise should maintain focus on their social mission, they conceded that there was need to consider economic motives that is akin to for-profit enterprises in order to remain sustainable. Opinion within the enterprise was however divided on how the social and the economic motives could co-exist in a social enterprise such as WAP and Ecosandals.com. Both Patrick and Mathew grappled with this tension. Patrick was embedded and accustomed to the ravages of poverty in Korogocho and naturally became averse to the social mission, and thus leaned more towards economic emancipation. On the other hand, Mathew being from wealthier surroundings in the USA had more 
altruistic environmental motives, and thus had a leaning towards a broader definition of the purpose of Ecosandals.com.

Apart from deciding on the operating model, the two partners also grappled with the survival and longevity of the operations of their enterprise. They wondered how they could innovate from the Ecosandals.com technology platform. Their focus was on how to expand their sphere of operations and thus to assist the wider Korogocho community in solving other problems within the community.

Lastly, as the partners contemplated the uncertain future, where digitization would become more and more entrenched, the need to develop more digital capabilities would require prioritization. The partners also needed to consider how to professionalize management by adopting governance mechanisms specifically related to digital technology - that would provide the leadership with effective and timeous decision-making tools. The challenge for the partners when considering governance issues was to recognize that WAP and Ecosandasl.com might metamorphose into a "giant" social enterprise since the number of stakeholders was increasing. With the enterprise expanding horizontally, the units in Michigan and Korogocho were likely to become more complex to manage; and as the customer base increased, orders - individual or batch, might need to become more project-based. How to evolve a governance structure that considers the changing dynamics remained a challenge?

\section{References}

Albinsson, P. A. and Yasanthi, P. B. (2012). Alternative marketplaces in the 21st century: Building community through sharing events. Journal of Consumer Behaviour, 11(4), pp. 303-315.

Austin, J., Stevenson, H. and Wei-Skillern, J. (2006). Social and commercial entrepreneurship: same, different, or both? Entrepreneurship Theory and Practice, 30(1), pp. 1-22.

Bloch, M., Pigneur, Y. and Segev, A. (1996). Leveraging electronic commerce for competitive advantage: A business value framework. In Proceeding of the Ninth International Conference on EDIISO, Bled, Slovenia. inproceedings.

Chell, E. (2007). Social enterprise and entrepreneurship towards a convergent theory of the entrepreneurial process. International Small Business Journal, 25(1), pp. 5-26.

Elkington, J. (1998). Partnerships from cannibals with forks: The triple bottom line of 21 st-century business. Environmental Quality Management, 8(1), pp. 37-51.

Espinosa, J. A., Boh, W. F. and DeLone, W. (January, 2011). The organizational impact of enterprise architecture: a research framework. System Sciences (HICSS) 44th Hawaii International Conference (pp. 1-10). IEEE.

Gathuthi, C., Muindi, M., Mwalali, T., Chiuri, M. and Kariuki, J. (2010). Korogocho socio-economic survey report-Final. Participatory Training Promotions Institute.

Panchal, P. (2016). Market Penetration Strategies of Retread Truck Tires in Kenya (Phd Thesis). United 
States International University-Africa.

Ross, J. W., Weill, P., \& Robertson, D. (2006). Enterprise architecture as strategy: Creating a foundation for business execution. Harvard Business Press. 


\section{Author}

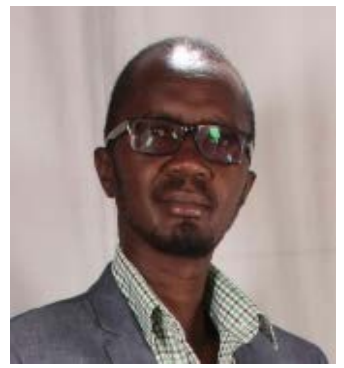

Nixon Muganda Ochara is a Research Associate Professor in the Department of Business Information Systems at the University of Venda. Prof. Ochara holds a PhD (Information Systems) from University of Cape Town, South Africa; an MBA (Management Information Systems) from University of Nairobi, Kenya. He has sustained a research focus on Digital Transformation, Inter-Organizational Information Systems; ICT Strategy \& Infrastructure Development; and Business Intelligence \& Analytics 


\section{Exhibit 1: Map of Kenya}

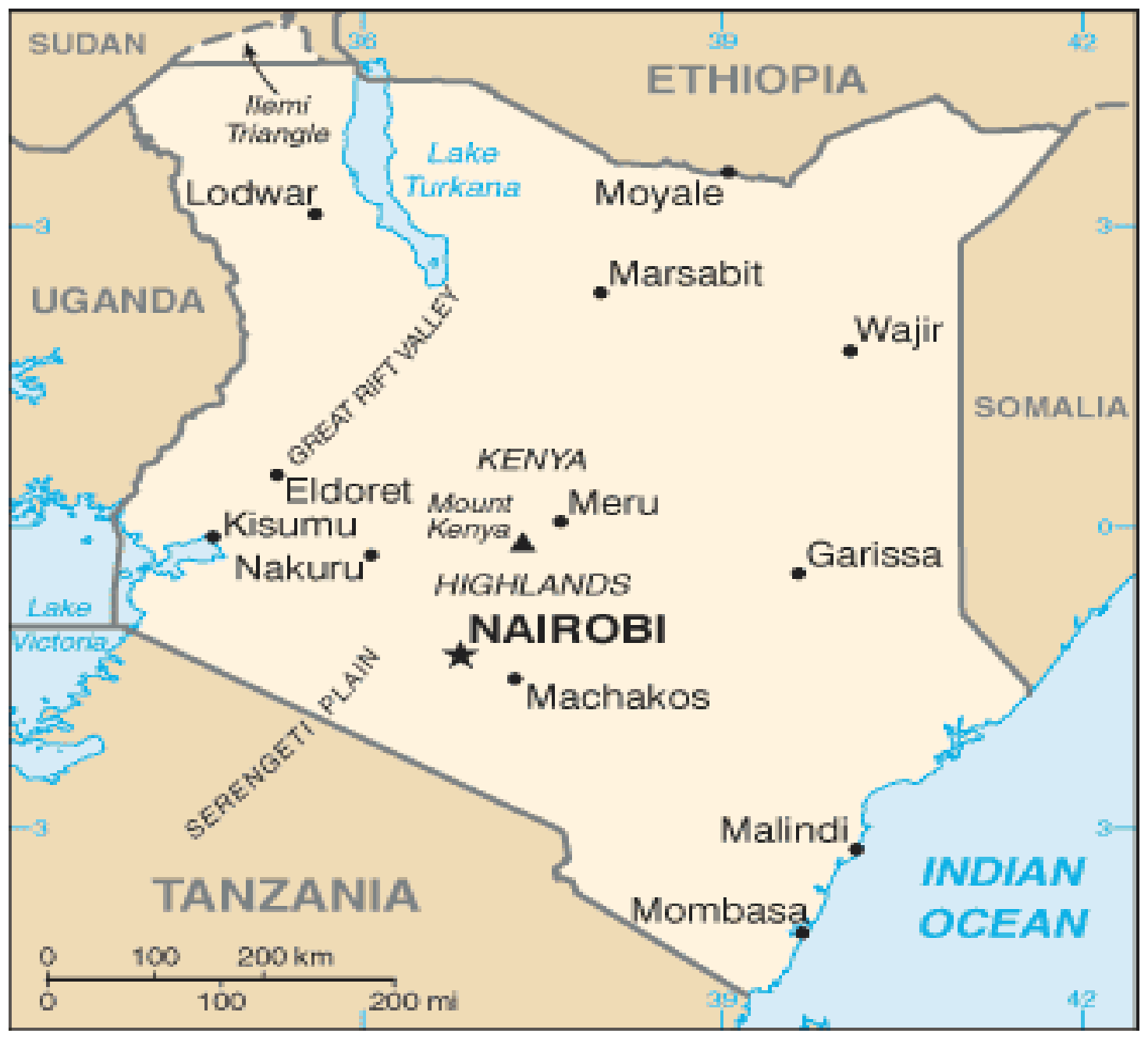

Figure 1 Map of Kenya 
Exhibit 2: Kenya: Key Indicators

\begin{tabular}{|l|l|l|}
\hline Indicator & Number & Source \\
\hline Population (2017 Estimate) & $50,217,787$ & UN-WPP, 2017 \\
\hline Literacy (2017) & $78 \%$ & CIA, 2017 \\
\hline GDP (2017 Estimate) & US\$ 74.7 billion & KNBS, 2017 \\
\hline Internet Users (April 2017) & 39.4 Million & CCK, 2008 \\
\hline
\end{tabular}




\section{Exhibit 3: Sample Eco Sandal}

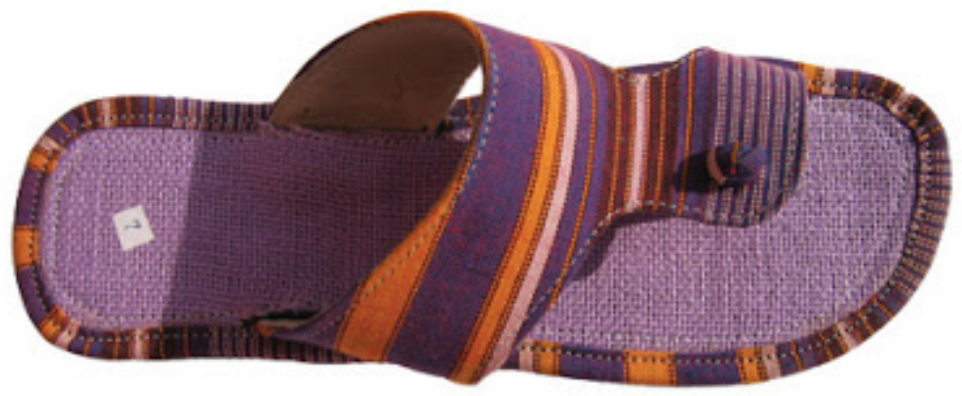

Source: Ecosandals.com 


\section{Exhibit 4: "Jua Kali" Artisans}

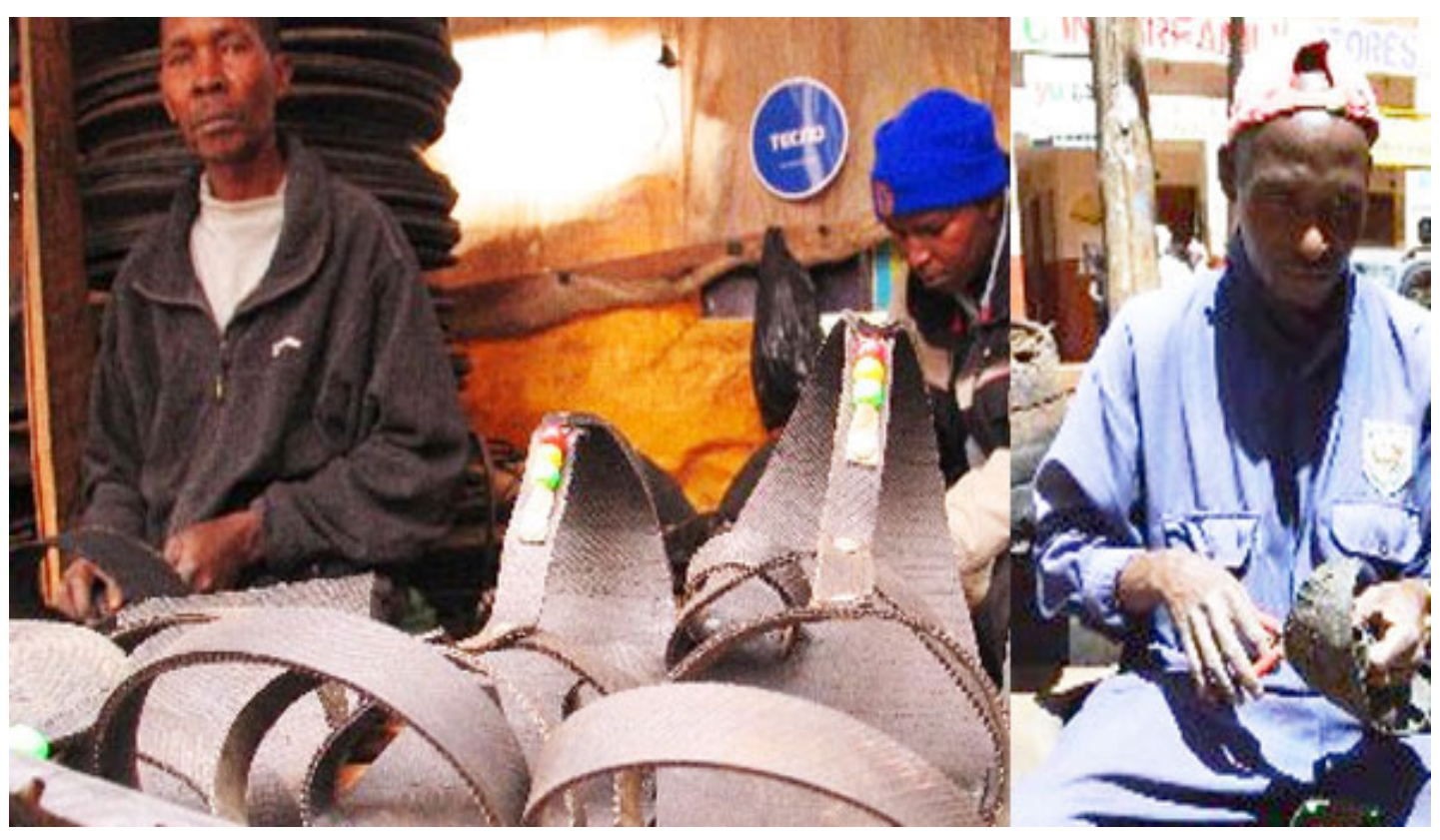

Source: Ecosandals.com 